\title{
Potential diagnostic value of serum p53 antibody for detecting colorectal cancer: A meta-analysis
}

\author{
RONGQIN MENG ${ }^{1 *}$, YANG WANG ${ }^{1 *}$, LIANG HE ${ }^{1 *}$, YUANQING HE $^{2}$ and ZEDONG DU ${ }^{1}$ \\ ${ }^{1}$ Department of Oncology, Chengdu 363 Hospital, Chengdu, Sichuan 610041; ${ }^{2}$ Department of Gastroenterology, \\ Guangyuan Third Hospital, Guangyuan, Sichuan 628000, P.R. China
}

Received May 17, 2017; Accepted December 4, 2017

DOI: $10.3892 / \mathrm{ol} .2018 .8070$

\begin{abstract}
Numerous studies have assessed the diagnostic value of serum p53 (s-p53) antibody in patients with colorectal cancer (CRC); however, results remain controversial. The present study aimed to comprehensively and quantitatively summarize the potential diagnostic value of s-p53 antibody in CRC. The present study utilized databases, including PubMed and EmBase, systematically regarding s-p53 antibody diagnosis in CRC, accessed on and prior to 31 July 2016. The quality of all the included studies was assessed using quality assessment of studies of diagnostic accuracy (QUADAS). The result of pooled sensitivity, pooled specificity, positive likelihood ratio (PLR) and negative likelihood ratio (NLR) were analyzed and compared with overall accuracy measures using diagnostic odds ratios (DORs) and area under the curve (AUC) analysis. Publication bias and heterogeneity were also assessed. A total of 11 trials that enrolled a combined 3,392 participants were included in the meta-analysis. Approximately $72.73 \%$ (8/11) of the included studies were of high quality (QUADAS score $>7$ ), and all were retrospective case-control studies. The pooled sensitivity was 0.19 [95\% confidence interval (CI), 0.18-0.21] and pooled specificity was 0.93 (95\% CI, 0.92-0.94). Results also demonstrated a PLR of 4.56 (95\% CI, 3.27-6.34), NLR of 0.78 (95\% CI, 0.71-0.85) and DOR of 6.70 (95\% CI, 4.59-9.76). The symmetrical summary receiver operating characteristic curve was 0.73 . Furthermore, no evidence of publication bias or heterogeneity was observed in the meta-analysis. Meta-analysis data indicated that s-p53 antibody possesses potential diagnostic value for CRC. However, discrimination power was somewhat limited due to the low sensitivity.
\end{abstract}

Correspondence to: Dr Zedong Du, Department of Oncology, Chengdu 363 Hospital, 108 SangShu Jie, Chengdu, Sichuan 610041, P.R. China

E-mail: amos1985@163.com

*Contributed equally

Key words: colorectal cancer, serum p53 antibody, diagnosis, meta-analysis

\section{Introduction}

Colorectal cancer (CRC) is one of the most common types of gastrointestinal cancer. Almost two million new cases of CRC are diagnosed every year, making CRC the third most common cancer and the fourth most common cancer-associated cause of mortality in the world (1-3). The risk of CRC increases in certain populations and is associated with risk factors including: Hereditary nonpolyposis CRC; inflammatory bowel disease; a family history of CRC; being of African American descent (4-6). Patients with CRC are typically asymptomatic and therefore it is difficult to the disease diagnose until advanced stages, where the disease becomes incurable. Early diagnosis and therapy is able to decrease the risk of CRC in this asymptomatic population; however, early diagnosis of CRC remains a challenge in clinical practice. Hence, identification of novel non-invasive diagnostic methods for early tumor detection in CRC is required $(7,8)$.

The tumor protein (TP) 53 gene is the most widely used tumor biomarker in detecting a potential tumor as p53 mutations are the most commonly observed mutations in different types of cancer. Furthermore, the majority of anti-p53 autoantibodies are produced in response to p53 mutation (9). In healthy cells a p53 nuclear phosphoprotein is expressed as a protein product of the $\mathrm{p} 53$ gene. In contrast with $\mathrm{p} 53$ protein, anti-p53 antibodies are rarely detected in the serum of healthy controls (10). Mutated p53 leads to the accumulation of nonfunctional protein due to the increased stability and increased half-life (several h) compared with wild type p53 (20 min) (10). The accumulated protein acts as an antigen, leading to the subsequent development of anti-p53 antibodies, which are detectable within tissues and blood $(10,11)$. Due to the expanding field of molecular biotechnology, numerous studies on the potential diagnostic value of s-p53 antibody in CRC have been conducted $(11,12)$. The primary aim of the present meta-analysis was to determine whether the s-p53 antibody may be a potential biomarker for the diagnosis of CRC, and confirmed the accuracy of s-p53 antibody for CRC diagnosis.

\section{Materials and methods}

Systematic review strategies. The present study systematically searched the following databases; Cochrane Library 
(http://www.cochranelibrary.com/), PubMed (https://www. ncbi.nlm.nih.gov/pubmed) and EmBase (https://www.elsevier. com/solutions/embase-biomedical-research) accessed on and prior to 31 July 2016. Articles investigating s-p53 antibodies being used for the detection of CRC were taken into account in the present study. The following combined search terms were used: 'Colorectal cancer', 'colorectal carcinoma', 'blood OR serum', 'seropositive OR serum antibody' and 'p53 OR tp53'. PubMed was used to identify associated articles, which were searched manually for associated functions and references (11). The study was conducted according to the meta-analysis of observational studies in epidemiology (MOOSE) guidelines $(12,13)$ for systemic reviews and meta-analysis was conducted using PRISMA.

Inclusion criteria. All articles were evaluated carefully and eligible articles were included if they met the following criteria: i) Studies investigating the diagnostic value of serum (s)-p53 antibody in CRC; ii) articles that diagnosed CRC using the established gold standard (pathological examination of biopsies) and also tested patient serum for the detection of anti-p53 prior to any treatment and used controls without any other cancer; iii) the results of the included articles on diagnostic accuracy were able to be summarized in a $2 \times 2$ table.

Exclusion criteria. The exclusion criteria were as follows: i) If the same author reported results of patients in several publications, only the most relevant one was selected; ii) if available data for analysis was not complete, the study was excluded; iii) all systematic reviews, meta-analyses, case reports and editorials were excluded.

Data extraction, data synthesis and quality assessment. All articles that were included in the present study were assessed by two different authors, any disagreements between the two authors were resolved by discussion. All the included studies were assessed using the quality assessment for studies of diagnostic accuracy (QUADAS) guidelines (14). The Cochrane Collaboration Methods group on screening and diagnostic tests recommended the 11 items of QUADAS. A QUADAS score of $\geq 7$ was considered as good quality and score of $<7$ was considered as suboptimal quality. The following data were extracted from the included studies: First author's name, year of publication, country of publication, golden criteria of diagnosis, threshold value(s), number of TP (true positive), FP (false positive), FN (false negative), TN (true negative) diagnoses, diagnosis time (the period of time between admission to hospital and diagnosis), stage of tumor (TNM; Japanese classification of colorectal carcinoma, 8th Edition) (15) and research methods. To avoid transcriptional errors all data were reviewed twice.

Statistical analysis. Meta DiSc statistical software (version 1.4; Universidad Complutense, Madrid, Spain) and STATA (version 14.0, Stata Corporation, College Station, TX, USA) were used to analyze the extracted data. The present study adopted standard methods previously recommended for the meta-analysis of diagnostic test evaluations (16). The sensitivity, specificity, positive and negative likelihood ratio (PLR and NLR), and $95 \%$ confidence intervals (CIs) were calculated with a random effects model according to the Mantel-Haensed method, as previously described (17). The diagnostic odds ratio (DOR) was determined using Moses' constant of linear method and was used to measure the accuracy, which indicates the change in diagnostic performance of the test under study per unit increase in the covariant (18). Summary receiver operating characteristic curves (SROC) were used to summarize overall test performance, and the area under the curve (AUC) was calculated. Additionally, the issue associated of sensitivities and specificities of $100 \%$ were solved by the default method of adding 0.5 to all cells within the diagnostic $2 \times 2$ table $(16,19)$.

The $\chi^{2}$ test was applied to detect heterogeneity in the included studies. Inter-study heterogeneity was assessed using the $\mathrm{I}^{2}$ test according to the following formula: $\mathrm{I}^{2}=100 \% \times$ (Cochran Q-degrees of freedom)/Cochran Q (20). Meta regression was conducted to detect the heterogeneity between studies. In order to detect cut-off threshold effects, Spearman's correlation coefficient was used to evaluate the association between sensitivity and specificity. A scatter plot of the inverse square root of the effective sample size (1/ESS1/2) vs. the diagnostic log odds ratio (lnDOR) was used to visually assess the publication bias is, and should demonstrate a symmetrical funnel shape (21).

\section{Results}

Literature search. A total of 206 abstracts and titles were identified following all search strategies as described in Fig. 1. A total of 136 records were retained in the present study following rejection of replication errors in the included records. In total, 94 articles were excluded, as they did not meet the aforementioned inclusion criteria on the basis of the titles and abstracts. Of the remaining 42 studies, 18 additional articles were excluded due to the lack of a study control, 13 studies were excluded from the meta-analysis due to the lack of s-p53 detection in serum. The final 11 articles included in the present study met all inclusion criteria and were of good quality (Tables I and II).

Characteristics of included research. A total of 11 clinical trials presenting the diagnostic value of s-p53 antibody for CRC diagnosis were investigated in the present study, demonstrating different characteristics. For example, studies included in the meta-analyses were conducted in different countries; 6 studies were conducted in Japan (22-27), 1 was conducted in the USA (28), 1 was conducted in Germany (29), 1 was conducted in France (30) and 2 were conducted in China $(31,32)$. The year of publication ranged between 1997 and 2011. All 11 studies were retrospective; however, 4 studies did not provide TNM stage data $(22,23,25,27)$. In total, 10 studies included health volunteers as a control and 1 used patients with benign disease as the control (32).

Threshold effect. Computation of the Spearman correction coefficient for the logit of sensitivity and logit of 1-specificity of s-p53 antibody calculated by metadisc was $0.518(\mathrm{P}=0.102)$ (data not shown), indicating that there was no threshold effect and positive correlations were not statistically significant.

Outcome of meta-analysis. The random-effects model was applied to pooled data as there were distinct definitions 
Table I. Main characteristics and results of the 11 eligible studies.

\begin{tabular}{|c|c|c|c|c|c|c|c|c|}
\hline Author/year & Country & $\begin{array}{c}\text { Ref. } \\
\text { standard }\end{array}$ & $\begin{array}{l}\text { Assay } \\
\text { method }\end{array}$ & Cut-off & $\mathrm{TP}$ & FP & $\mathrm{FN}$ & $\mathrm{TN}$ \\
\hline Shimada et al, 2003 & Japan & Unknown & ELISA & $1.3 \mathrm{U} / \mathrm{ml}$ & 46 & 23 & 146 & 371 \\
\hline Yoshizawa et al, 2007 & Japan & Histology & ELISA & mean+2SD & 43 & 44 & 39 & 305 \\
\hline Tagi et al, 2010 & Japan & Histology & ELISA & Unknown & 30 & 2 & 100 & 23 \\
\hline Hammel et al, 1997 & France & Histology & ELISA & Unknown & 14 & 0 & 40 & 24 \\
\hline Kojima et al, 2009 & Japan & Histology & ELISA & $6 \mathrm{u} / \mathrm{ml}$ & 9 & 0 & 36 & 22 \\
\hline Takeda et al, 2001 & Japan & Histology & ELISA & Index $\geq 1.1$ & 17 & 1 & 10 & 37 \\
\hline Lechpammer et al, 2003 & America & Histology & ELISA & Index $\geq 0 \mathrm{Abs}$ & 40 & 0 & 180 & 42 \\
\hline Broll et al, 2001 & Germany & Histology & ELISA & Index $\geq 0 \mathrm{Abs}$ & 20 & 0 & 110 & 44 \\
\hline Shiota et al, 2000 & Japan & Histology & ELISA & Unknown & 18 & 1 & 53 & 17 \\
\hline Wu et al, 2011 & China & Histology & ELISA & index $>1.7$ & 24 & 20 & 52 & 180 \\
\hline Tang et al, 2001 & China & Histology & ELISA & $10 \mathrm{u} / \mathrm{Ul}$ & 130 & 2 & 868 & 209 \\
\hline
\end{tabular}

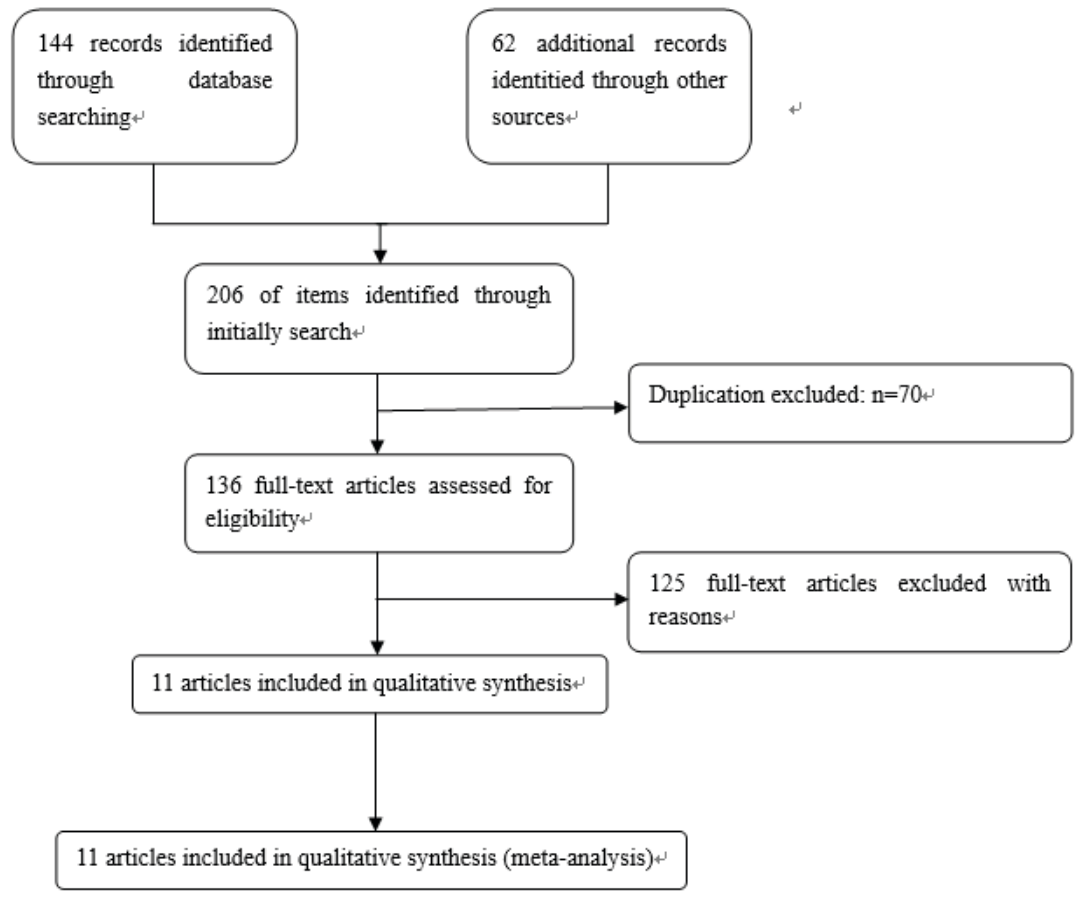

Figure 1. Flow chart of study selection using electronic databases.

of outcome and differing patient baseline characteristics between trials. Results presented in Fig. 2 demonstrate that the pooled DOR was 6.70 (95\% CI, 4.59-9.76), heterogeneity $\chi^{2}=11.99(\mathrm{P}=0.286)$ and $\mathrm{I}^{2}=16.60 \%$. In the present study, the symmetrical SROC of P-53 was 0.73 (Fig. 3). Thus, according to results of the present study, s-p53 antibody exhibited reasonable accuracy in terms of differential diagnosis in cases of CRC. The range of the sensitivity was between 13 and $63 \%$, pooled sensitivity was 0.19 (95\% CI, 0.18-0.21; Fig. 5), specificity was between 87 and $100 \%$ and pooled specificity was 0.93 (95\% CI, 0.92-0.94) (Figs. 4 and 5). In the present study, results demonstrated a pooled PLR of 4.56 (95\% CI, 3.27-6.34), suggesting that patients with CRC exhibited 4.56-fold increased chance of testing positive for s-p53 antibody compared with patients without CRC (Fig. 6).
Furthermore, the NLR was 0.78 (95\% CI, 0.71-0.85; Fig. 7). Significant heterogeneity was identified for all eligible studies. Heterogeneity $\chi^{2}=84.27(\mathrm{P}<0.001)$ and $\mathrm{I}^{2}=88.10 \%$.

Possible sources of heterogeneity. The meta-regression was adopted to explore the possible sources of heterogeneity, which included: Variation in the quality of methodology (QUADAS), study design, sample size, assay method, staging system (stage I \%) (TNM) and the time taken to collect and fix the sample. Meta-regression indicated that study design (pre- or post-treatment) [relative diagnostic odds ratio, 1.68; 95\% (0.65-4.36)] was the probable source of heterogeneity.

Publication bias evaluation and sensitivity analysis. Despite the studies included in the meta-analysis exhibiting some 
Table II. Main characteristics of the 11 eligible studies.

\begin{tabular}{|c|c|c|c|c|c|}
\hline Author, year & $\begin{array}{c}\text { Time of } \\
\text { specimen collection }\end{array}$ & $\begin{array}{c}\text { Stage I, } \\
\% \text { (proportion) }\end{array}$ & QUADAS & $\begin{array}{l}\text { Consecutive/ } \\
\text { random }\end{array}$ & (Refs.) \\
\hline Shimada et al, 2003 & Unknown & Unknown & 6 & Unknown & (22) \\
\hline Yoshizawa et al, 2007 & Unknown & Unknown & 7 & Consecutive & $(23)$ \\
\hline Tagi et al, 2010 & Unknown & $15 \%(19 / 130)$ & 8 & Unknown & (24) \\
\hline Hammel et al, 1997 & Prior to treatment & $19 \%(10 / 54)$ & 6 & Unknown & $(30)$ \\
\hline Kojima et al, 2009 & Unknown & $36 \%(16 / 45)$ & 7 & Unknown & (26) \\
\hline Takeda et al, 2001 & Prior to treatment & Unknown & 8 & Consecutive & (27) \\
\hline Lechpammer et al, 2003 & Prior to treatment & $12.7 \%(28 / 220)$ & 9 & Consecutive & (28) \\
\hline Broll et al, 2001 & Prior to treatment & $32 \%(41 / 130)$ & 8 & Unknown & (29) \\
\hline Shiota et al, 2000 & Prior to treatment & Unknown & 8 & Consecutive & (25) \\
\hline Wu et al, 2011 & Prior to treatment & $(2 / 67)$ & 8 & Consecutive & (31) \\
\hline Tang et al, 2001 & Before treatment & $25 \%(252 / 998)$ & 7 & Consecutive & (32) \\
\hline
\end{tabular}

QUADAS, quality assessment of studies of diagnostic accuracy.

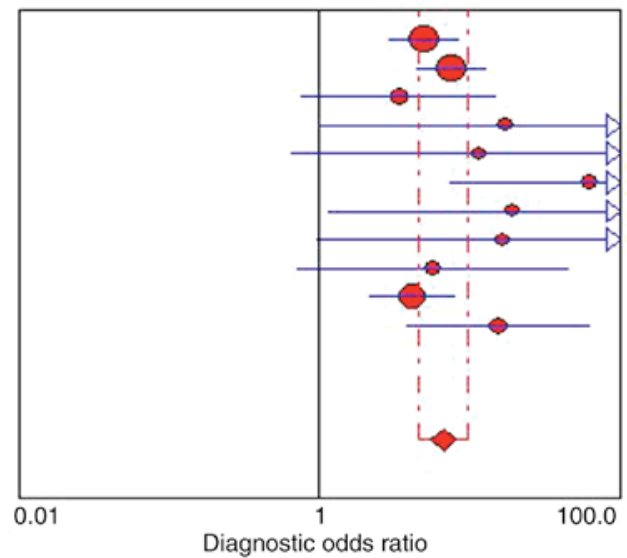

Shimada H. 2003

Yoshizawa S. 2007

Tagi T. 2010

Hammel P. 1997

Kojima T. 2009

Takeda A. 2001

Lechpammer M. 2003

Broll R. 2001

Shiota G. 2000

Wu J. 2011

Tang R. 2001

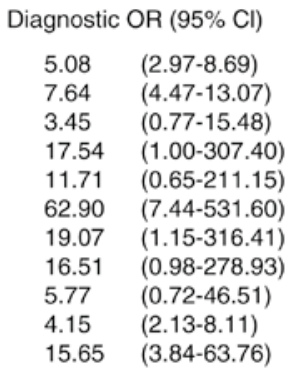

Random effects model

Pooled diagnostic odds ratio $=6.70$ (4.59 to 9.76$)$

Cochran- $Q=11.99 ; d f=10(p=0.2857)$

Inconsistency (I-square) $=16.6 \%$

Figure 2. Forest plot demonstrating estimates of the diagnostic odds ratio for serum p53 antibody in the diagnosis of CRC. Point estimates of the diagnostic odds ratio from each study are presented as a red diamond. CI, confidence interval; OR, odds ratio; CRC, colorectal cancer.

heterogeneity, the results of the present study demonstrated that no publication bias was detected by using Egger's test $(\mathrm{P}=0.72)$. Furthermore, the funnel plots (Fig. 6) used to detect publication bias also demonstrated no asymmetry upon visual inspection. Sensitivity analysis was conducted in terms of statistical analysis methods, study design and sample size. The results of sensitivity analysis produced no obvious changes. When the studies without matched cases and control sample size were excluded, results were not affected.

\section{Discussion}

The p53 gene comprises 20,000 base pairs spread over 11 exons located on 17 p13 (33-36). Discovered in 1979, it serves a critical function as a tumor-suppressor gene $(37,38)$. As previously established, the s-p53 antibody is not a specific biomarker for CRC $(34,35)$. However, positive associations have been reported between p53 immunoreactivity and the presence of s-p53 antibodies in patients with other types of cancer, including gastric carcinoma (39), esophageal

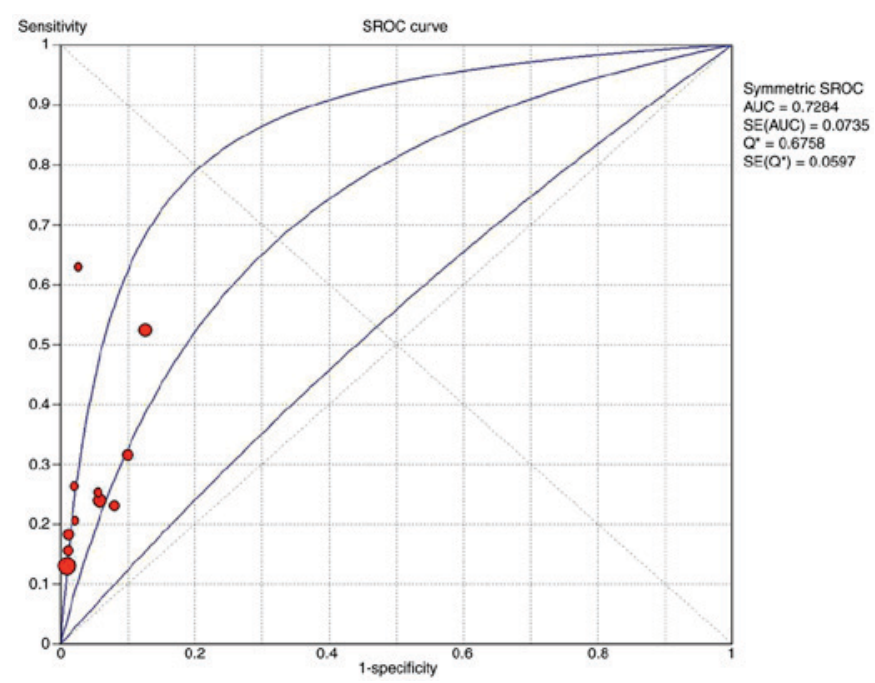

Figure 3. SROCs demonstrating serum p53 antibody in the diagnosis of CRC. Each solid circle represents each study in the meta-analysis. The size of each is indicated by the size of the solid circle SROC, summary receiver operating characteristic curves; AUC, area under the curve. 


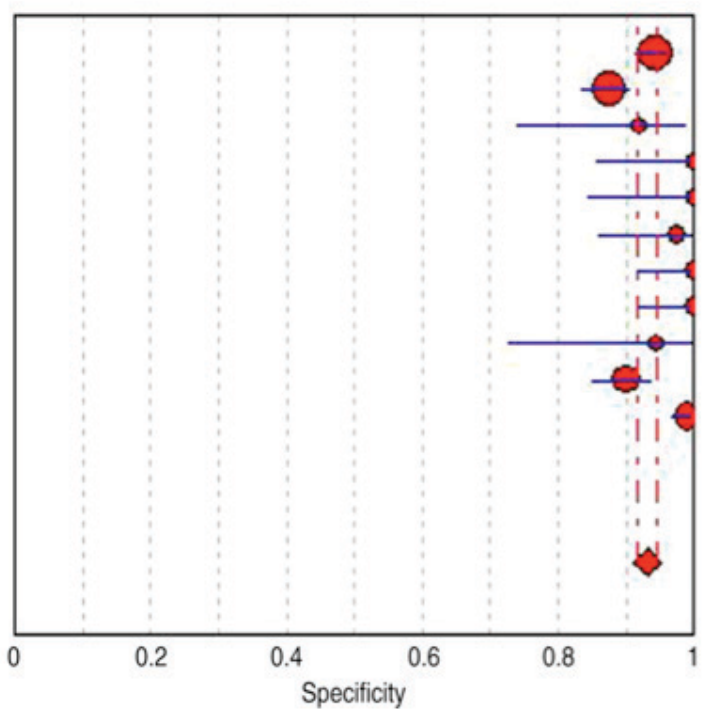

Shimada H. 2003

Yoshizawa S. 2007

Tagi T. 2010

Hammel P. 1997

Kojima T. 2009

Takeda A. 2001

Lechpammer M. 2003

Broll R. 2001

Shiota G. 2000

Wu J. 2011

Tang R. 2001
Specificity $(95 \% \mathrm{Cl})$

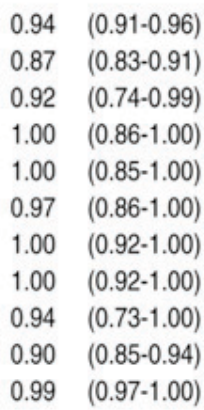

Pooled specificity $=0.93(0.92$ to 0.94$)$

Chi-square $=56.14 ; \mathrm{df}=10(\mathrm{P}<0.001)$

Inconsistency (I-square) $=82.2 \%$

Figure 4. Forest plot demonstrating the specificity of 11 individual studies for serum p53 antibody in the diagnosis of colorectal cancer. Point estimates of the specificity from each study are presented as a red diamond.

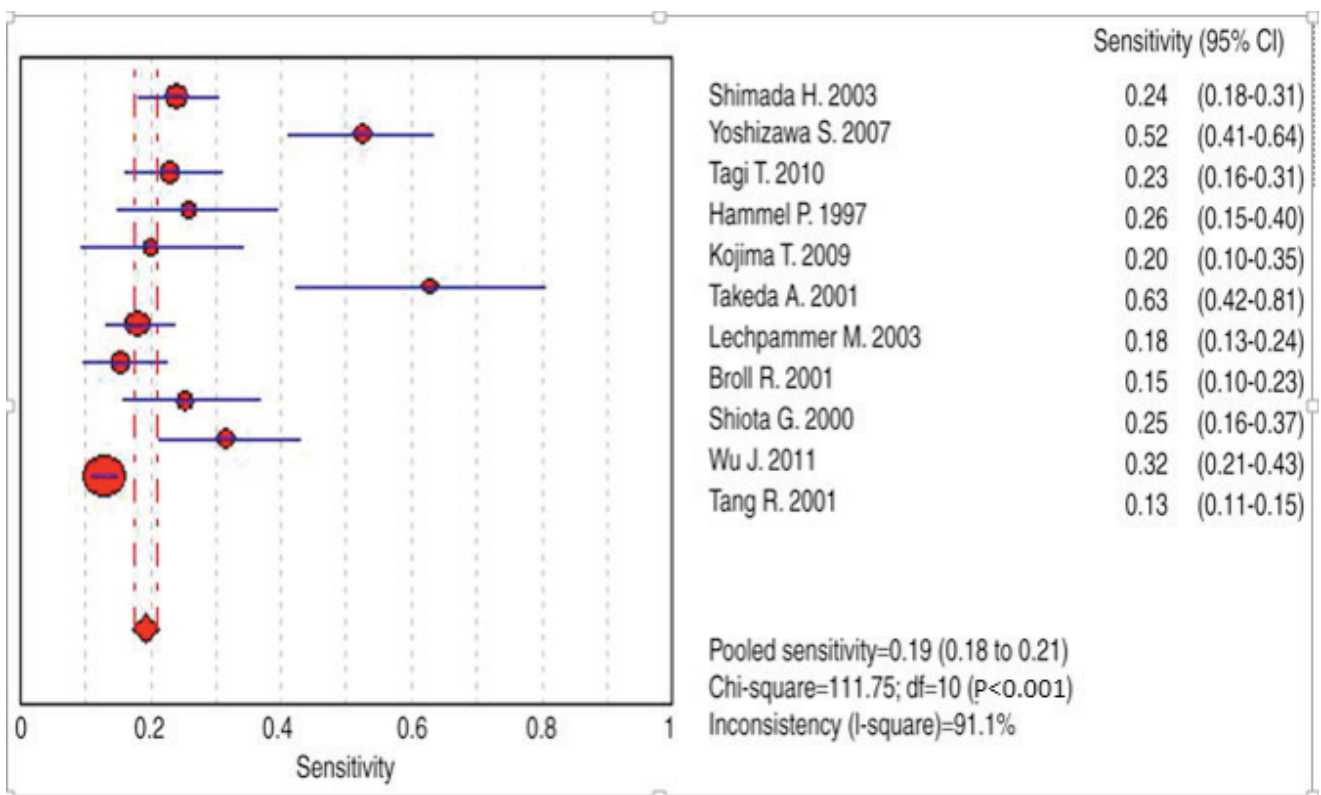

Figure 5. Forest plot demonstrating sensitivity of 11 individual studies for serum p53 antibody in the diagnosis of colorectal cancer. Point estimates of the sensitivity from each study are shown as a red diamond. CI, confidence interval; df, degrees of freedom.

carcinoma (40) and ovarian carcinoma (41). Previous studies on the molecular biology of malignant tumors have emphasized the importance of a number of proto-oncogenes and tumor suppressor genes in human malignancy. Thus, the identification of biomarkers that are capable of providing a definitive diagnosis in various types of malignancy is of high importance in order to provide improved management for patients (11).

$\mathrm{CRC}$ is one of the most commonly diagnosed cancers globally $(17,33)$. However, early detection of CRC remains challenging in clinical practice. To the best of our knowledge, there is currently no diagnostic biomarker for CRC. Recently, the s-p53 antibody has been widely utilized in clinical practice as a tumor biomarker for CRC; however, results vary between studies and no large-scale studies have been conducted which investigate the use of S-p53Ab as a diagnostic tool for patients with CRC $(4,20)$. The meta-analysis conducted in the present study was used to summarize the potential diagnostic value of s-p53 antibody for the early detection of CRC. The conclusions drawn from the meta-analysis are as follows: i) The pooled sensitivity was $0.19(95 \% \mathrm{CI}, 0.18-0.21)$ and the pooled specificity was 0.93 (95\% CI, 0.92-0.94); ii) patients with CRC have an increased chance of exhibiting a positive s-p53 test compared with patients without CRC; iii) the odd ratio for positive test for CRC was increased 5-fold compared with the odds ratio for positive test in non CRC. In brief, s-p53-antibody may 


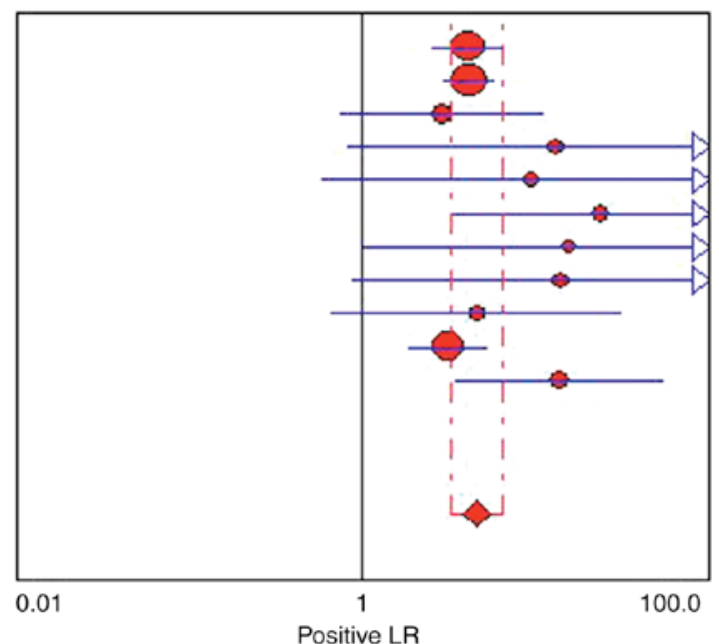

Shimada H. 2003

Yoshizawa S. 2007

Tagi T. 2010

Hammel P. 1997

Kojima T. 2009

Takeda A. 2001

Lechpammer M. 2003

Broll R. 2001

Shiota G. 2000

Wu J. 2011

Tang R. 2001
Positive LR $(95 \% \mathrm{Cl})$

$4.10 \quad(2.57-6.57)$

$4.16 \quad(2.95-5.87)$

$2.88 \quad(0.74-11.31)$

$13.18 \quad(0.82-212.32)$

$9.50 \quad(0.58-156.13)$

$23.93 \quad(3.39-169.10)$

$15.76 \quad(0.99-251.43)$

$14.08 \quad(0.87-228.13)$

$4.56 \quad(0.65-31.95)$

$3.16 \quad(1.86-5.37)$

$13.74 \quad(3.43-55.10)$

Random effects model

Pooled positive $\mathrm{LR}=4.56$ (3.27 to 6.34 )

Cochran- $Q=12.88 ; d f=10(p=0.2305)$

Inconsistency (I-square) $=22.4 \%$

Tau-squared $=0.0579$

Figure 6. Forest plot demonstrating estimates of positive likelihood ratio for s-p53 antibody in the diagnosis of colorectal cancer. Point estimates of the positive likelihood ratio from each study are presented as a red diamond. LR, likelihood ratio; CI, confidence interval; DF, degrees of freedom.

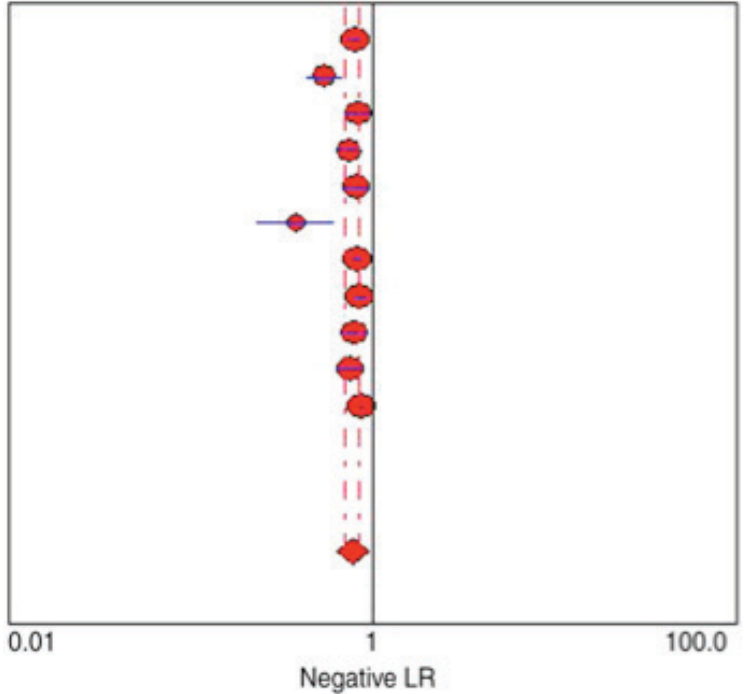

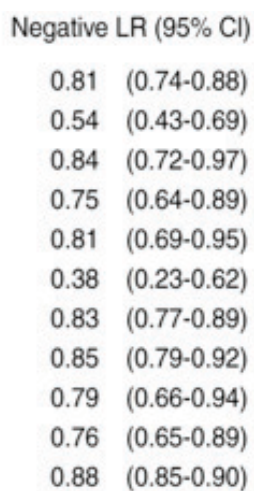

Random effects model

Pooled negative LR $=0.78$ ( 0.71 to 0.85 )

Cochran-Q=84.27; df=10 ( $P<0.001)$

Inconsistency (l-square) $=88.1 \%$

Tau-squared $=0.0170$

Figure 7. Forest plot demonstrating estimates of negative likelihood ratio for s-p53 antibody in the diagnosis of colorectal cancer. Point estimates of the negative likelihood ratio from each study are presented as a red diamond. LR, likelihood ratio; CI, confidence interval; df, degrees of freedom.

be useful for the detection and diagnosis of CRC; however, it is important to recognize that s-p53-antibody exhibits low sensitivity levels.

The results of the present study reveal that s-p53 may serve a significant function in screening for cancer, offering a convenient, noninvasive, low costs biomarker with the assumption that future research focuses on the following: i) Improve the sensitivity and specificity by combining additional serum tumor biomarkers; ii) use sputum, serum or other samples that are easy to acquire to improve sensitivity; iii) standardize the detection method and threshold values (lower threshold value leads to increased sensitivity and decreased specificity); iv) conduct normative diagnostic tests or collect samples from cases prior to biopsy in order to improve sensitivity. Collectively, these conditions may decrease the heterogeneity among the included studies, enabling future studies to conduct an accurate

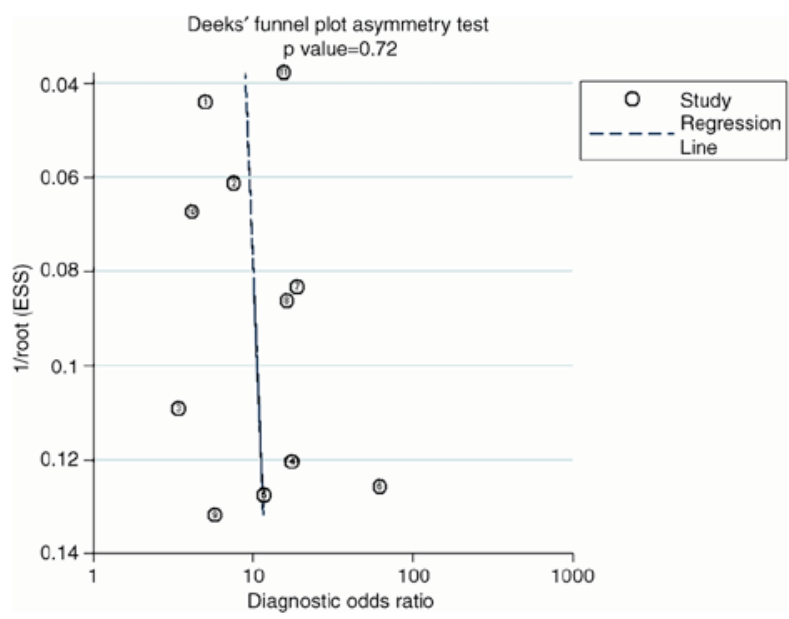

Figure 8. Funnel plot for the assessment of potential bias in serum p53 antibody assays. The dotted line is regression line. 
meta-analysis to identify the diagnostic value of the s-p53 antibody.

It is important to appreciate the limitations of the present study including: i) Lack of calculation for diagnostic accuracy for early stage (stage I-II) CRC due to lack of access to raw data; additionally, only five studies with small patient cohorts described the different stages of CRC; ii) all 11 included studies lacked the appropriate matching of age, location, and methods of obtaining and handling of the samples between case and control. Furthermore, large-scale studies are required to examine the association between s-p53 antibodies, disease staging and prognosis for patients with CRC. Collectively, this will assist in improving the treatment options for patients with CRC.

In conclusion, according to the results of the present study, s-p53 antibody demonstrated a potential diagnostic value with low sensitivity. Furthermore, patients with CRC have an increased chance of exhibiting a positive result for the p-53 antibody test compared with patients without CRC. Due to its high specificity, s-p53 antibody may be useful for monitoring residual tumor cells and aiding in the diagnosis of patients who have CRC. Larger scale research is required to identify the patterns of multiple biomarkers to further increase the power of CRC detection.

\section{Acknowledgements}

The authors wish to thank Wu Liang (Department of Oncology, Chengdu 363 Hospital) for analyzing the data.

\section{References}

1. International Agency for Research on Cancer (IARC): World Cancer Report 2014. Stewart B and Wild CP (eds). IARC, Lyon, 2014. http://publications.iarc.fr/Non-Series-Publications/WorldCancer-Reports/World-Cancer-Report-2014.

2. Brody H: Colorectal cancer. Nature 521: S1, 2015.

3. Mármol I, Sánchez-de-Diego C, Pradilla Dieste A, Cerrada E and Rodriguez Yoldi MJ: Colorectal carcinoma: A general overview and future perspectives in colorectal cancer. Int J Mol Sci 18 : pii: E197, 2017.

4. Komaki Y, Komaki F, Micic D, Ido A and Sakuraba A: Risk of colorectal cancer in chronic liver diseases; a systematic review and meta-analysis. Gastrointest Endosc 86: S93-S104.e5, 2017.

5. El-Shami K, Oeffinger KC, Erb NL, Willis A, Bretsch JK, Pratt-Chapman ML, Cannady RS, Wong SL, Rose J, Barbour AL, et al: American cancer society colorectal cancer survivorship care guidelines. CA Cancer J Clin 65: 428-455, 2015.

6. Giardiello F M, Allen JI, Axilbund JE, Boland CR, Burke CA, Burt RW, Church JM, Dominitz JA, Johnson DA, Kaltenbach T, et al: Guidelines on genetic evaluation and management of Lynch syndrome: A consensus statement by the US multi-society task force on colorectal cancer. Gastroenterol 147: 502-526, 2014

7. Corley DA, Levin TR and Doubeni CA: Adenoma detection rate and risk of colorectal cancer and death. N Engl J Med 370: 2541, 2014.

8. Loberg M, Kalager M, Holme $\varnothing$, Hoff G, Adami HO and Bretthauer M: Long-term colorectal-cancer mortality after adenoma removal. N Engl J Med 371: 799-807, 2014.

9. Levine AJ, Momand J and Finlay CA: The p53 tumour suppressor gene. Nature 351: 453-456, 1991.

10. Wu M, Mao C, Chen Q, Cu XW and Zhang WS: Serum p53 protein and anti-p53 antibodies are associated with increased cancer risk: A case-control study of 569 patients and 879 healthy controls. Mol Biol Rep 37: 339-343, 2010.

11. Zhang J, Xv Z, Wu X and Li K: Potential diagnostic value of serum p53 antibody for detecting esophageal cancer: A meta-analysis. PLoS One 7: e52896, 2012.
12. Stroup DF, Berlin JA, Morton SC, Olkin I, Williamson GD, Rennie D, Moher D, Becker BJ, Sipe TA and Thacker SB: Meta-analysis of observational studies in epidemiology: A proposal for reporting. Meta-analysis of observational studies in epidemiology (MOOSE) group. JAMA 283: 2008-2012, 2000.

13. Moher D, Liberati A, Tetzlaff J and Altman DG; PRISMA Group: Preferred reporting items for systematic reviews and metaanalyses: The PRISMA statement. Int J Surg 8: 336-341, 2010.

14. Smidt N, Deeks J and Moore T: Guide to the contents of a Cochrane review and protocol. Cochrane handbook for systematic reviews of diagnostic test accuracy, 2011.

15. Japanese Society for Cancer of the Colon and Rectum Japanese classification of colorectal carcinoma. The 8th edition. Kanehara \& CO., LTD, Tokyo, 2013.

16. Devillé WL, Buntinx F, Bouter LM, Montori VM, de Vet HC, van der Windt DA and Bezemer PD: Conducting systematic reviews of diagnostic studies: Didactic guidelines. BMC Med Res Methodol 2: 9, 2002.

17. DerSimonian R and Laird N: Meta-analysis in clinical trials. Control Clin Trials 7: 177-188, 1986.

18. Gu P, Huang G, Chen Y, Zhu C, Yuan J and Sheng S: Diagnostic utility of pleural fluid carcinoembryonic antigen and CYFRA 21-1 in patients with pleural effusion: A systematic review and meta-analysis. J Clin Lab Anal 21: 398-405, 2007.

19. Zhang J, Zhu Z, Liu Y, Jin X, Xu Z, Yu Q and Li K: Diagnostic value of multiple tumor markers for patients with esophageal carcinoma. PLoS One 10: e0116951, 2015.

20. Dinnes J, Deeks J, Kirby J and Roderick P: A methodological review of how heterogeneity has been examined in systematic reviews of diagnostic test accuracy. Health Technol Assess 9: 1-133, iii, 2005.

21. Deeks JJ, Macaskill P and Irwig L: The performance of tests of publication bias and other sample size effects in systematic reviews of diagnostic test accuracy was assessed. J Clin Epidemiol 58: 882-893, 2005.

22. Shimada H, Ochiai T and Nomura F: Titration of serum p53 antibodies in 1,085 patients with various types of malignant tumors: A multiinstitutional analysis by the Japan p53 Antibody Research Group. Cancer 97: 682-689, 2003.

23. Yoshizawa S, Matsuoka K, Inoue N, Takaishi H, Ogata H, Iwao Y, Mukai M, Fujita T, Kawakami Y and Hibi T: Clinical significance of serum p53 antibodies in patients with ulcerative colitis and its carcinogenesis. Inflamm Bowel Dis 13: 865-873, 2007.

24. Tagi T, Matsui T, Kikuchi S, Hoshi S, Ochiai T, Kokuba Y, Kinoshita-Ida Y, Kisumi-Hayashi F, Morimoto K, Imai T, et al: Dermokine as a novel biomarker for early-stage colorectal cancer. J Gastroenterol 45: 1201-1211, 2010.

25. Shiota G, Ishida M, Noguchi N, Oyama K, Takano Y, Okubo M, Katayama S, Tomie Y, Harada K, Hori K, et al: Circulating p53 antibody in patients with colorectal cancer: Relation to clinicopathologic features and survival. Dig Dis Sci 45: 122-128, 2000.

26. Kojima T, Yoshikawa K, Matsui T, Kodera Y and Kojima H: Titration of serum CEA, p53 antibodies and CEA-IgM complexes in patients with colorectal cancer. Mol Med Rep 2: 477-480, 2009.

27. Takeda A, Shimada H, Nakajima K, Yoshimura S, Suzuki T, Asano T, Ochiai T and Isono K: Serum p53 antibody as a useful marker for monitoring of treatment of superficial colorectal adenocarcinoma after endoscopic resection. Int J Clin Oncol 6: 45-49, 2001.

28. Lechpammer M, Lukač J, Lechpammer S, Kovacević D, Loda M and Kusić Z: Humoral immune response to p53 correlates with clinical course in colorectal cancer patients during adjuvant chemotherapy. Int J Colorectal Dis 19: 114-120, 2004.

29. Broll R, Duchrow M, Oevermann E, Wellm C, Schwandner O, Schimmelpenning H, Roblick UJ, Bruch HP and Windhövel U: p53 autoantibodies in sera of patients with a colorectal cancer and their association to $\mathrm{p} 53$ protein concentration and p53 immunohistochemistry in tumor tissue. Int J Colorectal Dis 16: 22-27, 2001.

30. Hammel P, Boissier B, Chaumette MT, Piedbois P, Rotman N, Kouyoumdjian JC, Lubin R, Delchier JC and Soussi T: Detection and monitoring of serum p53 antibodies in patients with colorectal cancer. Gut 40: 356-361, 1997.

31. Wu J, Qiu T, Pan P, Yu D, Ju Z, Qu X, Gao X, Mao C and Wang L: Detection of serum anti-P53 antibodies from patients with colorectal cancer in China using a combination of P53-and phage-ELISA: Correlation to clinical parameters. Asian Pac J Cancer Prev 12: 2921-2924, 2011. 
32. Tang R, Ko MC, Wang JY, Chen HH, Chen JS, Hsu KC, Chiang JM and Hsieh LL: Humoral response to p53 in human colorectal tumors: A prospective study of 1,209 patients. Int J Cancer 94: 859-863, 2001.

33. International Agency for Research on Cancer, World Health Organisation: IARC TP53 Database. Version R18. IARC, Lyon, 2016. http://p53.iarc.fr/. Accessed April, 2016.

34. Petitjean A, Mathe E, Kato S, Ishioka C, Tavtigian SV, Hainaut $P$ and Olivier M: Impact of mutant p53 functional properties on TP53 mutation patterns and tumor phenotype: Lessons from recent developments in the IARC TP53 database. Hum Mutat 28 622-629, 2007.

35. Suppiah A and Greenman J: Clinical utility of anti-p53 auto-antibody: Systematic review and focus on colorectal cancer. World J Gastroenterol 19: 4651-4670, 2013.

36. Soussi T, Dehouche K and Béroud C: p53 website and analysis of p53 gene mutations in human cancer: Forging a link between epidemiology and carcinogenesis. Hum Mutat 15: 105-113, 2000

37. Levine AJ: The common mechanisms of transformation by the small DNA tumor viruses: The inactivation of tumor suppressor gene products: p53. Virology 384: 285-293, 2009.
38. Staples OD, Steele RJ and Lain S: p53 as a therapeutic target. Surgeon 6: 240-243, 2008.

39. Maehara Y, Kakeji Y, Watanabe A, Baba H, Kusumoto H, Kohnoe $\mathrm{S}$ and Sugimachi K: Clinical implications of serum anti-p53 antibodies for patients with gastric carcinoma. Cancer 85: 302-308, 1999.

40. Ralhan R, Arora S, Chattopadhyay TK, Shukla NK and Mathur M: Circulating p53 antibodies, p53 gene mutational profile and product accumulation in esophageal squamous-cell carcinoma in India. Int J Cancer 85: 791-795, 2000.

41. Angelopoulou K, Rosen B, Stratis M, Yu H, Solomou M and Diamandis EP: Circulating antibodies against p53 protein in patients with ovarian carcinoma. Correlation with clinicopathologic features and survival. Cancer 78: 2146-2152, 1996.

(i) $\odot$ This work is licensed under a Creative Commons Attribution-NonCommercial-NoDerivatives 4.0 International (CC BY-NC-ND 4.0) License. 